\title{
Pelaksanaan Upah Kerja Lembur Pada Pt Asia Forestama Raya Berdasarkan Keputusan Menteri Tenaga Kerja Dan Transmigrasi Nomor Kep.102/Men/VI/2004
}

\author{
ANDREW SHANDY UTAMA; FAIZAH KAMILAH \\ Universitas Lancang Kuning \\ Jln. Yos Sudarso Km 08 Rumbai Telp. (0761) 52581 Fax. (0761) 52581 \\ E-mail : andrew.fh.unilak@gmail.com
}

\begin{abstract}
Pursuant to Article 78 of Law No. 13/2003 it is stated that companies which employ workers exceeding work hours as stipulated in Article 77 of the law are required to pay overtime wages. This research aims to explain the implementation of overtime wages at PT Asia Forestama Raya based on the Decree of the Minister of Manpower and Transmigration of the Republic of Indonesia No. Kep.102/Men/VI/2004 regarding Overtime and Overtime Wages. The method used in this research is socio-legal research. The results of the research explained that PT Asia Forestama Raya did not pay overtime wages to its factory workers who had worked more than hours worked as stipulated in Law No. 13/2003. The obstacle is because the company's financial condition is currently in an unstable condition and there is an agreement between the company management and factory workers that PT Asia Forestama Raya is unable to pay overtime wages to its workers. The legal settlement if PT Asia Forestama Raya does not pay overtime wages to its workers who have worked more than working hours, then the company may be subject to criminal sanctions under Article 187 of Law No. 13/2003.
\end{abstract}

Keywords: Law, Labour, Overtime Wages

Pembangunan ketenagakerjaan sebagai bagian integral dari pembangunan nasional berdasarkan Pancasila dan Undang-Undang Dasar Negara Republik Indonesia Tahun 1945 dilaksanakan dalam rangka pembangunan manusia Indonesia seutuhnya dan pembangunan masyarakat Indonesia seluruhnya untuk meningkatkan harkat, martabat, dan harga diri tenaga kerja serta mewujudkan masyarakat sejahtera, adil, makmur, dan merata, baik materiil maupun spiritual.

Pembangunan ketenagakerjaan harus diatur sedemikian rupa sehingga terpenuhi hak-hak dan perlindungan yang mendasar bagi tenaga kerja, serta pada saat yang bersamaan dapat mewujudkan kondisi yang kondusif bagi pengembangan dunia usaha.

Pembangunan ketenagakerjaan mempunyai banyak dimensi dan keterkaitan. Keterkaitan itu tidak hanya dengan kepentingan tenaga kerja selama, sebelum, dan sesudah masa kerja, tetapi juga keterkaitan dengan kepentingan pengusaha, pemerintah, dan masyarakat. Untuk itu, diperlukan pengaturan yang menyeluruh dan komprehensif, antara lain mencakup pengembangan sumber daya manusia, peningkatan produktivitas dan daya saing tenaga kerja Indonesia, upaya perluasan kesempatan kerja, pelayanan penempatan tenaga kerja, dan pembinaan hubungan industrial.

$\begin{array}{lllr}\text { Undang-Undang } & \text { Dasar } & \text { Negara } \\ \text { Republik Indonesia } & \text { Tahun } & 1945 \\ \text { mengamanatkan bahwa tiap-tiap } & \text { warga } \\ \text { negara berhak atas } & \text { pekerjaan } & \text { dan } \\ \text { penghidupan yang layak } & \text { bagi } \\ \text { kemanusiaan. Sejalan } & \text { dengan itu, }\end{array}$ Undang-Undang Nomor 13 Tahun 2003 tentang Ketenagakerjaan menegaskan bahwa setiap tenaga kerja memiliki kesempatan yang sama tanpa diskriminasi untuk memperoleh pekerjaan. Oleh karena itu, perlindungan terhadap hak-hak tenaga kerja merupakan tanggung jawab negara. Selain itu, perlindungan terhadap hak-hak tenaga kerja perlu terus disosialisasikan mengingat tidak semua tenaga kerja yang 
mengetahui hukum pada umumnya dan khususnya Undang-Undang Nomor 13 Tahun 2003 tentang Ketenagakerjaan (Suhendro, Andrew Shandy Utama, \& Ade Pratiwi Susanty, 2018).

Dalam rangka melindungi hak-hak tenaga kerja, Undang-Undang Nomor 13 Tahun 2003 tentang Ketenagakerjaan memberikan hak kepada tenaga kerja untuk membentuk serikat pekerja. Fungsi serikat pekerja yaitu (Asri Wijayanti, 2014):

1. Sebagai pihak dalam pembuatan Perjanjian Kerja Bersama dan penyelesaian perselisihan perburuhan.

2. Sebagai wakil dalam lembaga kerja sama.

3. Sebagai sarana menciptakan hubungan industrial yang harmonis, dinamis, dan berkeadilan.

4. Sebagai sarana penyalur aspirasi.

5. Sebagai perencana, pelaksana, dan penanggung jawab pemogokan buruh.

6. Sebagai wakil dalam memperjuangkan kepemilikan saham.

Salah satu hak tenaga kerja yang dilindungi hukum adalah hak waktu kerja. Berdasarkan Pasal 77 Undang-Undang Nomor 13 Tahun 2003 tentang Ketenagakerjaan dijelaskan bahwa setiap perusahaan wajib melaksanakan ketentuan waktu kerja, yaitu 7 jam perhari dan 40 jam perminggu untuk 6 hari kerja dalam seminggu atau 8 jam perhari dan 40 jam perminggu untuk 5 hari kerja dalam seminggu. Selanjutnya, berdasarkan Pasal 78 Undang-Undang Nomor 13 Tahun 2003 tentang Ketenagakerjaan ditegaskan bahwa perusahaan yang mempekerjakan tenaga kerjanya melebihi waktu kerja sebagaimana yang telah disebutkan di atas wajib membayar upah kerja lembur, yang cara perhitungannya diatur dalam Keputusan Menteri Tenaga Kerja dan Transmigrasi Republik Indonesia Nomor Kep.102/Men/VI/2004 tentang Waktu Kerja Lembur dan Upah Kerja Lembur.
Dari observasi penelitian yang dilakukan di PT Asia Forestama Raya, diperoleh informasi bahwa buruh pabrik yang bekerja pada bagian produksi tidak menerima upah kerja lembur meskipun telah bekerja melebihi waktu kerja sebagaimana yang diatur dalam Pasal 77 Undang-Undang Nomor 13 Tahun 2003 tentang Ketenagakerjaan.

Berdasarkan latar belakang permasalahan yang telah diuraikan di atas, maka rumusan masalah yang akan dibahas dalam penelitian ini yaitu sebagai berikut:

1. Bagaimana pelaksanaan upah kerja lembur pada PT Asia Forestama Raya berdasarkan Keputusan Menteri Tenaga Kerja dan Transmigrasi Republik Indonesia Nomor Kep.102/Men/VI/2004 tentang Waktu Kerja Lembur dan Upah Kerja Lembur?

2. Apa faktor-faktor yang menghambat dalam pelaksanaan upah kerja lembur pada PT Asia Forestama Raya berdasarkan Keputusan Menteri Tenaga Kerja dan Transmigrasi Republik Indonesia Nomor Kep.102/Men/VI/2004 tentang Waktu Kerja Lembur dan Upah Kerja Lembur?

3. Bagaimana penyelesaian hukum terhadap faktor-faktor yang menghambat dalam pelaksanaan upah kerja lembur pada PT Asia Forestama Raya berdasarkan Keputusan Menteri Tenaga Kerja dan Transmigrasi Republik Indonesia Nomor Kep.102/Men/VI/2004 tentang Waktu Kerja Lembur dan Upah Kerja Lembur?

Hukum ketenagakerjaan adalah seperangkat aturan, baik tertulis maupun tidak tertulis, yang mengatur pola hubungan industrial antara pemberi kerja di satu sisi dan penerima kerja di sisi yang lain (R. Joni Bambang S., 2013). Tujuan pokok hukum ketenagakerjaan adalah melaksanakan keadilan sosial dalam 
perburuhan dengan melindungi buruh terhadap kekuasaan yang tidak terbatas dari pihak pengusaha agar bertindak sesuai dengan kemanusiaan. Buruh dan pengusaha diberi kebebasan untuk mengadakan peraturan tertentu karena hukum perburuhan bersifat otonomi, tetapi peraturan ini tidak boleh bertentangan dengan peraturan pemerintah yang bermaksud mengadakan perlindungan terhadap buruh.

Hakikat hukum ketenagakerjaan adalah melindungi buruh dari tindakan sewenang-wenang pihak pengusaha. Secara yuridis, kedudukan buruh dan pengusaha itu sama. Secara sosial ekonomi, kedudukan buruh lebih rendah dari pengusaha. Oleh karena itu, diperlukan pemberdayaan dan proses kemitraan dalam bekerja yang dilindungi oleh undangundang (R. Joni Bambang S., 2013).

Secara yuridis, buruh memiliki kebebasan yang dilindungi oleh peraturan perundang-undangan yang berlaku. Artinya, buruh memiliki kedudukan yang sama di depan hukum dengan pengusaha, tetapi secara sosiologis, kedudukan buruh tersubordinasi oleh pengusaha, yang artinya pengusaha memiliki kewenangan untuk memerintah buruh serta menetapkan syaratsyarat kerja dan keadaan perburuhan. Dengan kata lain, kedudukan pengusaha lebih tinggi daripada kedudukan buruh dalam hubungan perburuhan. Secara sosiologis, buruh adalah orang yang tidak memiliki bekal hidup selain mengandalkan tenaganya, sehingga terpaksa bekerja pada pengusaha, dan pengusaha yang menentukan syarat-syarat diterima atau tidaknya buruh untuk bekerja. Dengan demikian, kedudukan pengusaha lebih dominan daripada buruh, tetapi bukan berarti pengusaha bebas memperlakukan buruh sebagaimana melakukan perbudakan dan memeras tenaganya tanpa mengikuti peraturan perundang-undangan yang berlaku. Oleh karena itu, antara buruh dan pengusaha memerlukan perjanjian kerja yang mengatur pola kerja dan pola pengupahannya (Hardijan Rusli, 2011).
Secara teoritis, terdapat tiga jenis perlindungan kerja, yaitu (Soedarjadi, 2008):

1. Perlindungan sosial, yaitu jenis perlindungan yang berkaitan dengan usaha kemasyarakatan yang memungkinkan buruh mengenyam dan mengembangkan kehidupannya sebagaimana manusia pada umumnya, khususnya sebagai anggota keluarga dan anggota masyarakat. Perlindungan sosial biasanya disebut juga dengan kesehatan kerja.

2. Perlindungan teknis, yaitu jenis perlindungan yang berkaitan dengan usaha-usaha untuk menjaga agar buruh terhindar dari bahaya kecelakaan yang ditimbulkan oleh alat-alat atau bahan yang digunakan dalam bekerja. Perlindungan teknis biasanya disebut juga dengan keselamatan kerja.

3. Perlindungan ekonomis, yaitu jenis perlindungan yang berkaitan dengan usaha-usaha untuk memberikan kepada buruh suatu penghasilan yang cukup untuk memenuhi keperluan sehari-hari baginya dan keluarganya, termasuk dalam hal buruh tidak mampu bekerja karena sesuatu yang terjadi di luar kehendaknya. Perlindungan ekonomis biasanya disebut juga dengan jaminan sosial.

Pada tahun 2018, dalam penelitian yang berjudul "Perlindungan Tenaga Kerja terhadap Pengaturan Waktu Kerja di PT Quality Solution”, Said Fani menjelaskan bahwa karyawan PT Quality Solution telah bekerja melebihi waktu kerja, tetapi pihak perusahaan tidak memberikan upah kerja lembur kepada karyawannya. Upaya yang dilakukan oleh karyawan PT Quality Solution apabila pihak perusahaan tidak memberikan upah kerja lembur yaitu melaporkannya kepada 
Dinas Tenaga Kerja Kota Pekanbaru (Said Fani, 2018).

Selain itu, dalam penelitian yang berjudul "Pemenuhan Hak-hak Pekerja Waktu Tertentu pada PT Wiratama Jaya Perkasa Ditinjau Berdasarkan UndangUndang Nomor 13 Tahun 2003 tentang Ketenagakerjaan”, Alika Nanda Frisri menjelaskan bahwa dalam perjanjian kerja antara PT Wiratama Jaya Perkasa dan karyawannya tidak ada diatur mengenai upah kerja lembur apabila karyawan bekerja melebihi waktu kerja dikarenakan keterbatasan keuangan perusahaan. Karyawan PT Wiratama Jaya Perkasa juga tidak mengetahui bahwa upah kerja lembur merupakan hak karyawan yang diatur dalam Undang-Undang Nomor 13 Tahun 2003 tentang Ketenagakerjaan (Alika Nanda Frisri, 2018).

Apabila mencermati berbagai ulasan dalam tinjauan kepustakaan sebagaimana yang dijelaskan di atas, maka tidak ditemukan pembahasan mengenai pelaksanaan upah kerja lembur pada PT Asia Forestama Raya berdasarkan Keputusan Menteri Tenaga Kerja dan Transmigrasi Republik Indonesia Nomor Kep.102/Men/VI/2004 tentang Waktu Kerja Lembur dan Upah Kerja Lembur. Kalaupun ada pembahasan mengenai pelaksanaan upah kerja lembur, penelitian tersebut dilaksanakan di lokasi yang berbeda dengan penelitian ini.

\section{METODE}

Penelitian hukum adalah suatu kegiatan ilmiah yang didasarkan pada metode, sistematika, dan pemikiran tertentu yang bertujuan untuk mempelajari satu atau beberapa gejala hukum tertentu dengan jalan menganalisanya (Soerjono Soekanto, 2007). Metode yang digunakan dalam penelitian ini adalah penelitian hukum sosiologis dengan menggunakan pendekatan pelaksanaan hukum terhadap masyarakat. Penelitian hukum sosiologis bertujuan yaitu untuk mengetahui bagaimana hukum itu dilaksanakan, termasuk proses penegakan hukum. Hal ini karena penelitian hukum sosiologis dapat mengungkapkan permasalahan-permasalahan yang ada di balik pelaksanaan dan penegakan hukum (Amiruddin dan Zainal Asikin, 2012).

Sumber data yang digunakan dalam penelitian ini adalah data primer dan data sekunder. Data primer yaitu data yang diperoleh langsung dari hasil observasi dan wawancara di lokasi penelitian, sedangkan data sekunder yaitu data yang diperoleh dari jurnal-jurnal ilmiah, literatur hukum, dan peraturan perundang-undangan. Teknik pengumpulan data yang digunakan dalam penelitian ini adalah observasi, wawancara, dan studi kepustakaan. Teknik analisis data yang digunakan dalam penelitian ini adalah analisis kualitatif.

\section{HASIL}

Undang-Undang Nomor 13 Tahun 2003 tentang Ketenagakerjaan merupakan dasar hukum yang mengatur mengenai hubungan hukum di bidang ketenagakerjaan antara pengusaha dan buruh di Indonesia, termasuk di PT Asia Forestama Raya. PT Asia Forestama Raya merupakan pabrik pengolahan kayu hasil hutan untuk bahan baku industri kayu. PT Asia Forestama Raya mulai beroperasi di Kota Pekanbaru sejak tahun 1986 dengan nama PT Rantau Jaya Sakti, yang berkedudukan di Kelurahan Limbungan. Saat ini, perusahaan tersebut mempekerjakan ratusan orang buruh yang sebagian besarnya bekerja sebagai buruh pabrik dengan status tenaga kerja kontrak.

Berdasarkan Undang-Undang Nomor 13 Tahun 2003 tentang Ketenagakerjaan disebutkan bahwa hak-hak buruh yang berstatus tenaga kerja kontrak yaitu hak mendapatkan perlakuan yang sama tanpa diskriminasi (Pasal 6), hak mendapatkan pelatihan kerja (Pasal 12 Ayat 3), hak memilih penempatan kerja (Pasal 31), tidak ada masa percobaan kerja (Pasal 58 Ayat 1), waktu kerja yang jelas (Pasal 77 Ayat 2), adanya waktu kerja lembur (Pasal 78 Ayat 1), hak menerima upah kerja lembur (Pasal 78 Ayat 2), hak mendapatkan waktu istirahat dan cuti (Pasal 79 Ayat 2), 
adanya waktu untuk beribadah wajib (Pasal 80), hak libur bekerja bagi tenaga kerja perempuan yang haid (Pasal 81 Ayat 1), hak libur bekerja bagi tenaga kerja perempuan yang melahirkan (Pasal 82), hak istirahat bekerja bagi tenaga kerja perempuan yang menyusui (Pasal 83), perlindungan atas keselamatan dan kesehatan kerja (Pasal 86 Ayat 1), hak menerima penghasilan yang layak (Pasal 88 Ayat 1), hak menerima upah sesuai dengan standar upah minimum (Pasal 90 Ayat 1), hak mendapatkan jaminan sosial tenaga kerja (Pasal 99 Ayat 1), hak menerima uang pesangon (Pasal 156 Ayat 2), dan hak menerima uang penghargaan masa kerja (Pasal 156 Ayat 3).

Buruh pabrik yang bekerja pada bagian produksi di PT Asia Forestama Raya dibagi dalam 2 shift kerja dengan waktu kerja 7 jam perhari selama 6 hari kerja dalam seminggu. Akan tetapi, buruh pabrik tersebut setiap harinya lembur bekerja hingga waktu pergantian shift tanpa adanya tambahan upah. Seharusnya perusahaan yang mempekerjakan buruhnya melebihi waktu kerja sebagaimana yang diatur dalam Pasal 77 Undang-Undang Nomor 13 Tahun 2003 tentang Ketenagakerjaan wajib membayar upah kerja lembur. Selain itu, waktu kerja lembur hanya diizinkan maksimal 3 jam dalam sehari.

Oleh karena itu, PT Asia Forestama Raya diwajibkan untuk membayar upah kerja lembur kepada buruh pabriknya yang telah bekerja melebihi waktu kerja. Peraturan teknis yang mengatur mengenai cara perhitungan upah kerja lembur yaitu Keputusan Menteri Tenaga Kerja dan Transmigrasi Republik Indonesia Nomor Kep.102/Men/VI/2004 tentang Waktu Kerja Lembur dan Upah Kerja Lembur. Adapun rumus menghitung upah kerja lembur untuk 1 jam bekerja yaitu:

$$
\text { Upah kerja lembur }=\frac{1}{173} \times \text { Upah perbulan }
$$

Jadi, jika buruh pabrik PT Asia Forestama Raya menerima upah perbulan sebagaimana standar Upah Minimum Kota (UMK) untuk Kota Pekanbaru tahun 2019 sebesar Rp 2.672.852,-, maka upah kerja lembur yang harus dibayarkan oleh pihak perusahaan adalah sebesar Rp 15.450,- untuk 1 jam lembur bekerja. Akan tetapi, buruh pabrik tersebut tidak ada menerima tambahan upah yang bersumber dari upah kerja lemburnya.

Faktor-faktor yang menghambat dalam pelaksanaan upah kerja lembur pada PT Asia Forestama Raya berdasarkan Keputusan Menteri Tenaga Kerja dan Transmigrasi Republik Indonesia Nomor Kep.102/Men/VI/2004 tentang Waktu Kerja Lembur dan Upah Kerja Lembur yang pertama adalah kondisi keuangan perusahaan tersebut yang saat ini sedang dalam keadaan yang tidak stabil sehingga tidak mampu untuk membayar upah kerja lembur kepada buruh pabriknya. Sebagaimana diketahui bahwa saat ini sangat sulit untuk mendapatkan kayu hasil hutan dengan harga yang murah karena adanya larangan penebangan hutan secara ilegal oleh pemerintah. Selain itu, buruh pabrik yang bekerja di PT Asia Forestama Raya tidak ada yang mempermasalahkan mengenai tidak dibayarkannya upah kerja lemburnya. Hal ini dikarenakan sebelumnya telah disepakati bersama oleh manajemen perusahaan dan buruh pabrik bahwa kondisi keuangan perusahaan dalam keadaan yang tidak stabil sehingga tidak mampu untuk membayar upah kerja lembur. Meskipun demikian, perusahaan tersebut tetap memberikan upah perbulan kepada buruh pabriknya sesuai dengan standar Upah Minimum Kota (UMK) untuk Kota Pekanbaru tahun 2019 yaitu sebesar Rp 2.672.852,-.

\section{PEMBAHASAN}

Hukum ketenagakerjaan di satu sisi bersifat privat dan di sisi lain bersifat publik. Hukum ketenagakerjaan bersifat privat artinya bahwa terdapat hubungan hukum antara pengusaha dan buruh yang didasarkan pada perjanjian kerja. Hukum ketenagakerjaan bersifat publik artinya bahwa adanya intervensi dari pemerintah 
dalam melindungi hak-hak buruh serta adanya sanksi dari peraturan perundangundangan bagi pengusaha yang melanggarnya (R. Joni Bambang S., 2013).

Oleh karena itu, meskipun PT Asia Forestama Raya dan buruh pabrik yang bekerja di perusahaan tersebut telah membuat kesepakatan terkait tidak adanya upah kerja lembur kepada buruh yang telah bekerja melebihi jam kerja sebagaimana yang diatur dalam Pasal 77 Undang-Undang Nomor 13 Tahun 2003 tentang Ketenagakerjaan, Dinas Tenaga Kerja Kota Pekanbaru sebagai instansi pemerintah yang berwenang melindungi hak-hak tenaga kerja di Kota Pekanbaru dapat memberikan sanksi administrasi kepada manajemen PT Asia Forestama Raya dalam bentuk peringatan tertulis agar perusahaan tersebut mematuhi Undang-Undang Nomor 13 Tahun 2003 tentang Ketenagakerjaan.

Selain itu, Undang-Undang Nomor 13 Tahun 2003 tentang Ketenagakerjaan juga mengatur adanya sanksi pidana bagi perusahaan yang melanggarnya. Berdasarkan Pasal 187 Undang-Undang Nomor 13 Tahun 2003 tentang Ketenagakerjaan ditegaskan bahwa perusahaan yang tidak membayarkan upah kerja lembur kepada tenaga kerjanya dapat dikenakan sanksi pidana kurungan paling singkat 1 bulan dan paling lama 12 bulan dan/atau denda paling sedikit $\mathrm{Rp}$ 10.000.000,- (sepuluh juta rupiah) dan paling banyak Rp 100.000.000,- (seratus juta rupiah). Jadi, PT Asia Forestama Raya dapat dikenakan sanksi pidana apabila tidak membayarkan upah kerja lembur kepada buruh pabriknya.

\section{SIMPULAN}

PT Asia Forestama Raya tidak membayarkan upah kerja lembur kepada buruh pabriknya yang telah bekerja melebihi jam kerja sebagaimana yang diatur dalam Undang-Undang Nomor 13 Tahun 2003 tentang Ketenagakerjaan. Hambatannya karena kondisi keuangan perusahaan tersebut saat ini sedang dalam keadaan yang tidak stabil serta adanya kesepakatan antara manajemen perusahaan dan buruh pabrik bahwa PT Asia Forestama Raya tidak mampu untuk membayarkan upah kerja lembur kepada buruhnya. Penyelesaian hukumnya apabila PT Asia Forestama Raya tidak membayar upah kerja lembur kepada buruhnya yang telah bekerja melebihi jam kerja, maka perusahaan tersebut dapat dikenakan sanksi pidana berdasarkan Pasal 187 Undang-Undang Nomor 13 Tahun 2003 tentang Ketenagakerjaan.

PT Asia Forestama Raya sebaiknya memberikan upah kerja lembur kepada buruh pabriknya yang telah bekerja melebihi jam kerja sebagaimana yang diatur dalam Undang-Undang Nomor 13 Tahun 2003 tentang Ketenagakerjaan.

\section{DAFTAR RUJUKAN}

Alika Nanda Frisri, 2018, Pemenuhan Hakhak Pekerja Waktu Tertentu pada PT Wiratama Jaya Perkasa Ditinjau Berdasarkan UndangUndang Nomor 13 Tahun 2003 tentang Ketenagakerjaan, JOM Fakultas Hukum Universitas Riau, Vol. V No. 1.

Amiruddin dan Zainal Asikin, 2006, Pengantar Metode Penelitian Hukum, Rajawali Pers, Jakarta.

Asri Wijayanti, 2014, Hukum Ketenagakerjaan Pasca Reformasi, Sinar Grafika, Jakarta.

Hardijan Rusli, 2011, Hukum Ketenagakerjaan, Ghalia Indonesia, Bogor.

Lalu Husni, 2015, Pengantar Hukum Ketenagakerjaan, Rajawali Pers, Jakarta.

R. Joni Bambang S., 2013, Hukum Ketenagakerjaan, Pustaka Setia, Bandung.

Said Fani, 2018, Perlindungan Tenaga Kerja terhadap Pengaturan Waktu 
Kerja di PT Quality Solution, JOM Fakultas Hukum Universitas Riau, Vol. V No. 1.

Soedarjadi, 2008, Hukum Ketenagakerjaan di Indonesia; Panduan bagi Pengusaha, Pekerja, dan Calon Pekerja, Pustaka Yustisia, Yogyakarta.

Soerjono Soekanto, 2007, Pengantar Penelitian Hukum, Rajawali Pers, Jakarta.

Suhendro, Andrew Shandy Utama, \& Ade Pratiwi Susanty, 2018, Peningkatan Pemahaman Karyawan PT Asia Forestama Raya Mengenai Perlindungan Hak-hak Tenaga Kerja Kontrak Berdasarkan UndangUndang Nomor 13 Tahun 2003 tentang Ketenagakerjaan, Jurnal Pengabdian Masyarakat Multidisiplin, Vol. 3 No. 2, 236-242.

Yetniwati. 2017. "Pengaturan Upah Berdasarkan atas Prinsip Keadilan". Jurnal Mimbar Hukum, Volume 29 Nomor 1. 